\title{
Quantification and at-risk period of decreased fertility associated with exposure to bluetongue virus serotype 8 in naïve dairy herds
}

\author{
S. Nusinovici, ${ }^{\star} \dagger \neq$ H. Seegers, ${ }^{\star} \dagger \neq$ A. Joly, ${ }^{\star} \dagger \neq$ F. Beaudeau, ${ }^{\star} \dagger \neq$ and C. Fourichon ${ }^{\star} \dagger \neq{ }^{1}$ \\ ${ }^{*}$ Oniris, UMR1300 Biologie, Epidémiologie et Analyse de Risque, La Chantrerie, BP 40706, F-44307 Nantes, France \\ †INRA, UMR1300, F-44307 Nantes, France \\ łLUNAM, Université Nantes, Angers, Le Mans, France
}

\section{ABSTRACT}

The detrimental effect of bluetongue virus serotype 8 (BTV-8) on fertility was quantified in seroconverting cows. Although the effect on individual cows provides information regarding the potential biological burden of infection, losses at a herd level are also dependent on the proportion of infected cows within the herd. The objectives of this study were to quantify the average effect of BTV-8 exposure in field conditions on the fertility of dairy cows in previously naïve herds, and to determine the at-risk period of decreased fertility related to the date of detection of the disease in the herd. The effect of BTV-8 exposure on fertility was assessed using the 90-d-return-to-service rates after the first artificial insemination (AI) calculated for cows in exposed herds (during the 2007 epizootic in France) and compared with that for cows in unexposed herds. Only herds with a confirmed detection that were reported after clinical suspicion were included. To determine the at-risk period of decreased fertility, variations of fertility in exposed herds were quantified according to the time interval between the date of AI for individual cows and the date that disease was detected in the herd. Survival analyses were used to assess the risk of decreased fertility associated with BTV-8 exposure, adjusting for the main factors known to influence fertility. The episode at risk for decreased fertility depended on the month of disease detection in the herd. For herds detected early in the epizootic, fertility was decreased for cows inseminated from 1 mo before to 1 mo after the date of disease detection in the herd. Depending on time interval between the date of AI of cows and the date of detection in the herd, the increase of return-to-service rate associated with BTV-8 exposure varied from 8 to 21 percentage points of 90 -d return to service. The episode of decreased fertility is likely due to a combination of the effect of the infection at different stages of conception and early pregnancy and the delayed exposure of

Received August 4, 2011.

Accepted January 11, 2012.

${ }^{1}$ Corresponding author: christine.fourichon@oniris-nantes.fr cows due to the spreading of the virus within herds. For herds detected during the second half of the epizootic, fertility was decreased for cows inseminated more than 2 mo before detection, which suggests a delay in the detection of clinical signs following virus introduction in the herd. No correlation was observed between the effect of BTV-8 exposure on fertility and the incidence of BTV-8 in the local geographical area. Given the duration of the period that cows were at risk for decreased fertility and the magnitude of the effect, the average BTV-8 exposure in naïve herds led to major losses.

Key words: bluetongue, fertility, cow, epidemiology

\section{INTRODUCTION}

Bluetongue is a noncontagious, insect-transmitted disease of domestic and wild ruminants caused by the bluetongue virus (BTV). Bluetongue virus serotype 8 (BTV-8) emerged in northern Europe in 2006 (mainly the Netherlands, Belgium, and Germany). In continental France, the first BTV-8 clinical case was reported in August 2006 near the border with Belgium. Subsequently, the disease re-emerged in 2007 and 2008, resulting in a respective 10,500 and 26,500 herds officially reported with clinical signs.

The BTV-8 epizootic in northern Europe had a major economic impact due to control measures and production losses (Saegerman et al., 2008; Velthuis et al., 2010). Production losses included mortality, decreased milk production, weight loss, and decreased reproductive performance (Velthuis et al., 2010). For a precise economic evaluation, quantitative estimation of the average effect of BTV-8 exposure of herds on performance is necessary. The average effect at the herd level can differ whether the disease is emerging, epizootic, or occurs in a population partly protected by vaccination.

The effects of BTV on reproductive performance in cattle include a wide range of reproductive disorders such as decreased fertility, abortions, stillbirth, and congenital abnormalities (Uhaa et al., 1990; Osburn, 1994; Elbers et al., 2008, 2009; Méroc et al., 2008; Dal Pozzo et al., 2009; Wouda et al., 2009). The ability to infect the conceptus has been demonstrated for BTV-8 
(Menzies et al., 2008; Dal Pozzo et al., 2009). Bluetongue virus serotype 8 could, thus, have a higher detrimental effect on reproductive performance compared with the other serotypes. The only published study that quantified the decreased fertility was conducted at the cow level (Santman-Berends et al., 2010). Cows that seroconverted during the 2008 epizootic in the Netherlands had a higher return-to-service rate at $56 \mathrm{~d}$ after AI. No estimates were available at the herd level.

The time period when the herd is at risk for decreased fertility around the disease detection is also of interest and has not been investigated. When a case of bluetongue is detected in a herd, a detrimental effect on fertility can be expected both before and after the date of the detection of the disease. The impact in the herd results from the progressive spreading of the virus within the herd. After the disease detection, a decrease in fertility can be due to the delayed exposure of some cows or to a delayed effect of the infection.

At the herd level, the average effect of exposure depends on the proportion of infected cows in the herd. In previously naïve populations, the within-herd prevalence has been shown to be related to the between-herd prevalence in a study conducted in France during the winter of 2007 (Durand et al., 2010). At the end of the 2007 epizootic, reported cattle herds located in the most affected areas (herd-level prevalence equal to 1) had a within-herd prevalence of between 0.42 and 0.99 , whereas those located in areas with an intermediate herd-level prevalence (around 60\% infected herds) had a within-herd prevalence that was lower than 0.10. Therefore, the average effect of BTV-8 exposure on fertility in a herd can be expected to vary according to the proportion of infected herds in the local geographical area.

The objectives of this study were to quantify the average effect under field conditions of BTV-8 epizootic exposure on the fertility of dairy cows in previously naïve herds for which the clinical signs were reported to the authorities and to determine the duration of the period when cows were at risk for decreased fertility both before and after the first detection of the disease in the herd. Furthermore, the influence of the proportion of case herds in the local geographical area of the herd on the effect of BTV-8 exposure on fertility was investigated. This study focused on effects of BTV-8 exposure on early pregnancy (i.e., from conception to the beginning of the fetal development).

\section{MATERIALS AND METHODS}

\section{General Study Design and Available Data}

Exposed herds from the 2007 French epizootic were selected to quantify the effect of BTV-8 exposure in a naïve cow population that had not been vaccinated against BTV-8. In 2006, only 6 exposed herds were reported in France. The reproductive performance of cows inseminated before and after the date that disease was detected in exposed herds and of cows in unexposed herds was compared.

Information on BTV-8 case herds was obtained from the official surveillance system. Herds were reported in 2 distinct situations: 1) in the event of clinical signs detected by the farmer or the veterinary practitioner, subsequently confirmed by a diagnostic test and 2) in the event of a positive serological test performed either before animal transfer or sale, or in sentinel herds. Herds with a confirmed detection, which were reported after clinical suspicion (situation 1) were included in the analyses. The other case herds (situation 2) were excluded because the date of a positive serological test did not necessarily reveal the possible date of BTV-8 exposure of the herd in that case, but was dependent on the decision to do a test. Herds reported after clinical signs in 2007 were located in 39 departments (the French metropolitan territory is divided into 95 departments). The numbers of reported case herds greatly varied among these departments. Reported herds located in 19 departments were selected, corresponding to $92 \%$ of all cattle herds reported due to clinical suspicion during the 2007 epizootic. Information about BTV-8 exposure was available at the herd level only (the BTV8 status was unknown at the cow level). Thus, a herd was considered exposed if at least 1 animal with clinical signs had tested positive for BTV-8. Herds reported after clinical suspicion and subsequently selected for this study will be referred to as case herds.

Performance data were obtained for dairy herds enrolled in the official Milk Recording Scheme and where AI was used. Data obtained included the dates of AI, rank of service, and data used to adjust for factors known to influence fertility: cow and bull breeds, parity, calving date, milk production data at each test-day record (date of the test day, milk yield, protein content, and fat content), and date of culling.

\section{Definition of Herd Exposure According to the Spatiotemporal Pattern of the Epizootic}

For each case herd, available data included the dates that clinical signs of disease were first suspected and the dates that disease was confirmed with diagnostic tests. The proportion of infected animals in reported herds was unknown. It was assumed that the proportion of infected cows in an exposed herd was related to the proportion of newly reported herds in a local geographical area (Durand et al., 2010). Because some herds did not have clinical signs when the infection 
had a subclinical course, or because, in the event of clinical expression, farmers could have not seen or reported the signs, reported herds underestimated the true exposure to BTV-8. Nevertheless, geographical areas were classified according to the proportion of case herds in their area, assuming that large variations in this proportion reflected variations in local BTV-8 exposure (termed level of BTV-8 exposure hereafter). Thus, exposed herds were categorized according to the level of BTV-8 exposure in their local area. The geographical unit considered to estimate the level of exposure was the canton (French district). The average number of cattle herds by canton was 47 in 2007. Cantons with a total number of cattle herds $<10$ were excluded because it was assumed that the estimation of the level of exposure was less accurate in cantons with such a small number of herds. To account for the spatiotemporal pattern of the epizootic (for a description, see Pioz et al., 2011), a level of exposure was attributed to each canton according to the peak monthly incidence of case herds. Cantons were classified in 3 categories of exposure: high and rapid (peak of monthly incidence $\geq 0.25$ ), intermediate (peak of monthly incidence $\geq 0.10$ and $<0.25$ ), and low and protracted (peak of monthly incidence $<0.10$ ). Accordingly, cantons were termed highly, moderately, and slightly exposed, respectively. The monthly incidence was defined as the number of newly reported herds in a given month in a canton divided by the total number of herds in the canton in 2007. A constant at-risk population was considered to avoid a bias related to the under-notification of cases during the French epizootic (Durand et al., 2010). If only non-cases had been considered as at risk, an increasing number of false-negative herds would bias the calculation of incidence, and this bias would have increased with time. Moreover, a constant at-risk population enabled us to determine the period during which a local peak incidence (highest number of new case herds) occurred. The incidence was calculated by including all the cattle herds, both beef and dairy, in the canton.

As the vector density is seasonal, it was assumed that the effect of BTV-8 exposure could vary according to the month of the peak. To more accurately identify the time of exposure, only case herds that were reported during the peak of the local monthly incidence were selected, as these herds were less likely to experience a delay in detection. However, as in the slightly exposed cantons, the incidence pattern was protracted and without a clear peak, this restriction was not applied. The criterion used to select and classify the case herds are summarized in Figure 1.

\section{Estimated Date of Exposure}

The date of exposure was estimated as the recorded date of suspicion that corresponded to the first detection of clinical signs in the herd. The same date of exposure was assigned to all cows in a herd. In $6.1 \%$ of the case herds, the date of suspicion was missing (621 out of the 10,182 reported cattle herds with clinical signs) but a date of confirmation of BTV-8 (positive test after detection of clinical signs) was available. To include herds with missing dates of suspicion and thereby increase the statistical power of the study, a date of suspicion was imputed. An imputation method based on the distribution of the time interval between dates of suspicion and confirmation was applied to interpolate the missing dates. First, the time interval between dates of suspicion and confirmation was calculated for each reported herd. Second, this time interval was fitted to a negative binomial function according to the month of confirmation, assuming that the time required to confirm a case could vary dependent upon the stage of the epizootic (e.g., with preparedness or capacity of the diagnostic laboratory). Then, a random selection was performed for each missing time interval in the fitted distributions and the corresponding missing dates of suspicion were calculated.

To improve accuracy, non-plausible time intervals between the dates of suspicion and confirmation were excluded. For 57 reported herds, the time interval between the date of suspicion and the date of confirmation was longer than $30 \mathrm{~d}$. According to the BTV National Reference Laboratory for diagnostic tests (ANSES, Maisons-Alfort, France), this time interval is not likely; therefore, these herds were excluded. Moreover, 124 herds were excluded because their dates of suspicion were later than the dates of confirmation. After these exclusions, the population of reported case herds based on clinical signs in 2007 included 8,279 cattle herds located in 534 cantons.

\section{Selection of Unexposed Cows}

Two reference populations of cows unexposed to BTV-8 were considered to limit selection bias and check the robustness of the results. The first reference population was composed of cows located in 2 regions unexposed to BTV-1 and BTV-8 viruses during 2007: Brittany and a southwestern area of France. In France, herd management varies between areas. Therefore, unexposed cows from 2 different parts of France were selected to better represent the unexposed population. This comparison limited the effect of any possible confounding factors due to variations of herd manage- 
BTV-8 clinical cattle case herds

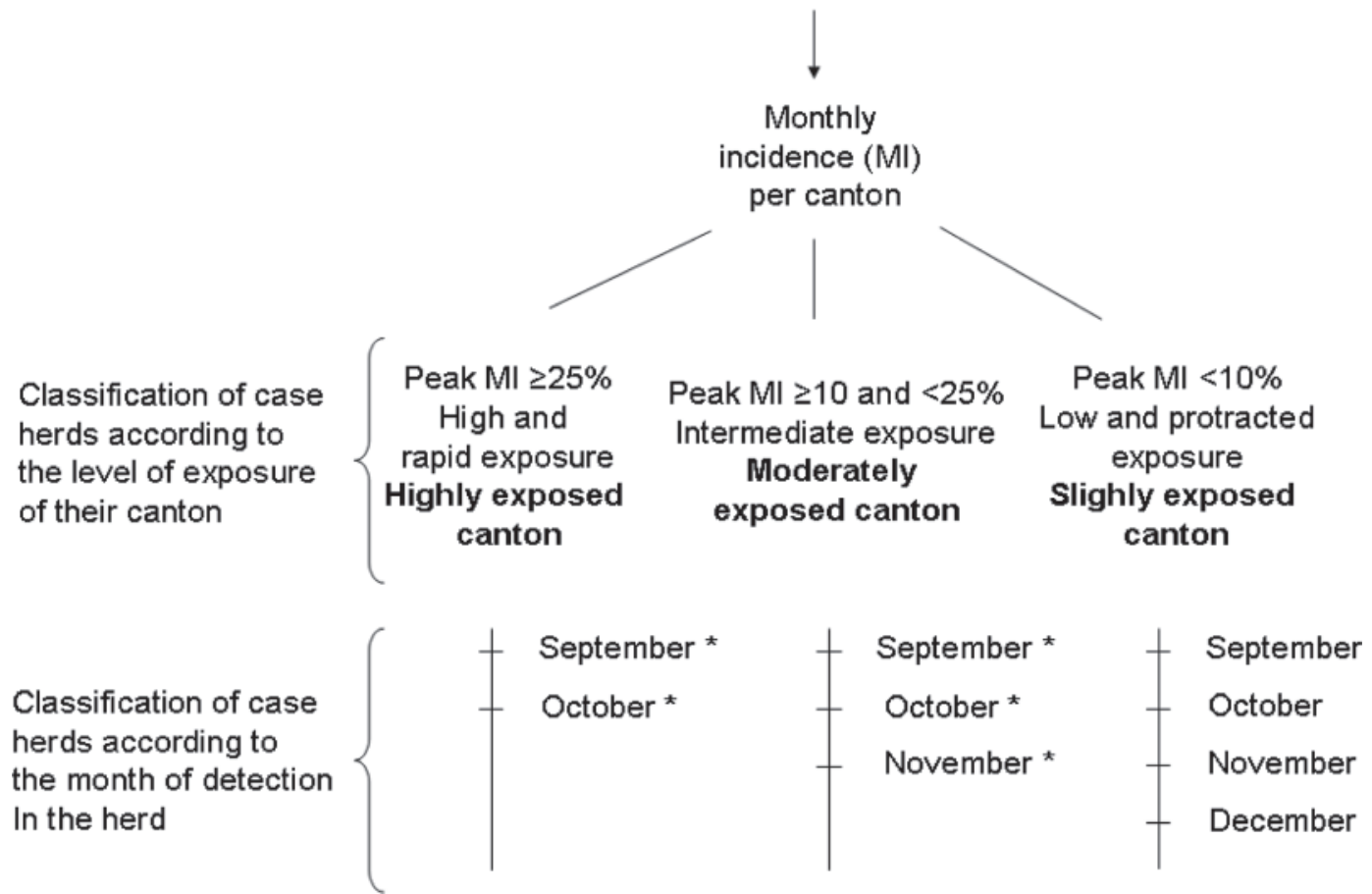

Figure 1. Classification of bluetongue virus serotype 8 (BTV-8) case herds according to the level of exposure of cantons and the month of detection in the herd. Monthly incidence $=$ number of new reported herds in a given month in a canton divided by the total number of herds in the canton in $2007 ; *$ indicates that the case herd was detected during the month of peak incidence in the canton.

ment with time. The second reference population was composed of information from cows of case herds before exposure in 2007 (2005 and 2006). This comparison limited possible confounding factors due to variations of herd management between different regions. The fact that the fertility of Holstein cows remained stable in France between 2005 and 2007 permitted an unbiased comparison (Le Mezec et al., 2010). The 2 reference populations were termed area-based and time-based reference populations, respectively.

The month of AI is known to influence the reproductive performance (Malher et al., 2006; Marcé et al., 2009). Consequently, unexposed cows were selected according to the date of AI such that cows from exposed herds and unexposed cows underwent AI during the same period in the year.

\section{Reproductive Performance Parameters and Data Selection}

Reproductive performance was assessed using the occurrence of a repeat AI following the first AI. As most farmers are likely to reinseminate the cow in the event of a return to estrus after the first AI, a repeat AI (return to service) can be used as a proxy for infertility.
A similar indicator has already been used in several studies to quantify the detrimental effect of disease on reproductive performance (Robert et al., 2004; Malher et al., 2006; Marcé et al., 2009; Santman-Berends et al., 2010). The calving rate could also be used to assess the reproductive performance. Although the calving rate depends on all events that occur during the pregnancy, the return to service, observed soon after AI, is likely to be associated with conception failure or embryonic death. Therefore, use of this parameter helps identify when the reproductive dysfunction occurred.

The parameter used to quantify effect of BTV-8 exposure on fertility was the 90-d return to service, defined as a return to service occurring between 18 and $90 \mathrm{~d}$ after AI. This interval included $91 \%$ of return to service. It was assumed that BTV-8 exposure could have 3 possible effects on fertility: conception failure, embryonic death, and fetal death in early gestation, all resulting in the same outcome: return to service.

Classification bias for reproductive status can occur when cows are culled before the next calving because pregnancy status at culling is not routinely available. Therefore, cows culled within $300 \mathrm{~d}$ following AI were excluded from analysis because their pregnancy status was uncertain. Cows with missing data (parity, milk 
yield, or date of the test day), nonplausible or extreme data were excluded [i.e., calving to first $\mathrm{AI}$ interval $<35$ d or $>180 \mathrm{~d}$, AI to calving interval $>297 \mathrm{~d}$ or $<175 \mathrm{~d}$, interval between $\mathrm{AI}>200 \mathrm{~d}$ or $<3 \mathrm{~d}$, interval between 2 test-day records $>85 \mathrm{~d}$ or $<20 \mathrm{~d}$, peak milk yield (expressed as the maximum at the 3 first test-day records) $>60 \mathrm{~kg} / \mathrm{d}$ or $<10 \mathrm{~kg} / \mathrm{d}$, and maximum fat:protein ratio out of the 3 first test-day records $>4$ or $<0.67]$. Herds with unusual management (unusual demographic structure, delayed first service, or very small herds) or herds likely to have used a bull also were excluded. Only data from Holstein cows inseminated with semen from Holstein bulls were selected because a strong effect of breed on reproductive performance exists (Heins et al., 2006; Lucy, 2007). Heifers were excluded because their fertility differs from that of cows (Raheja et al., 1989). After these exclusions, the study population was composed of 1,039,350 cows with a first AI from a total of 16,776 herds $(3,313$ herds that notified clinical signs and 13,463 herds unexposed to BTV-8 in 2007).

\section{Comparisons to Quantify and Determine the At-Risk Period for Decreased Fertility}

Selection and Classification of AI According to Exposure. All AI performed from 10 wk before to 4 wk after the date of BTV-8 detection in herds were selected. These were classified into categories according to the time interval between the date the AI was performed and the date of exposure to BTV-8 in the herd, the level of exposure at the canton level, and the month of exposure of the herd. Between the dates of AI of cows and the date of exposure in the herd, intervals of $15 \mathrm{~d}$ were considered (see Results for categories).

Selection and Classification of AI to Determine the At-Risk Period for Decreased Fertility. All AI performed from $14 \mathrm{wk}$ before to 14 wk after the date of BTV-8 detection in the herd were selected. Time intervals each of 1-wk duration were considered to precisely determine the at-risk period. It was assumed that the interlude between the virus introduction and the disease detection was more homogeneous (with less risk of delayed detection) when the monthly incidence was high. Further, it was assumed that this interlude was probably shorter for herds reported earlier in the epizootic (September) than for herds reported later. Therefore, only herds for which disease was detected in September in highly exposed cantons were included.

\section{Statistical Models}

The relationship between exposure and occurrence of a possible return to service was assessed using multivariable Cox models. To account for factors likely to influence the probability of return to service, the association between BTV-8 exposure and occurrence of return to service was adjusted for several independent variables already described as risk factors for fertility traits in the literature (Hillers et al., 1984; Seegers, 1998; Robert et al., 2004; Malher et al., 2006; Marcé et al., 2009), as described by Equation 1:

$$
\begin{aligned}
\mathrm{Y}_{\mathrm{ijklmno}}=\alpha & +\mathrm{EXP}_{\mathrm{i}}+\mathrm{LN}_{\mathrm{j}}+\mathrm{MY}_{\mathrm{k}}+\mathrm{PF}_{1}+\mathrm{CAII}_{\mathrm{m}} \\
& +\mathrm{MO}_{\mathrm{n}}+\mathrm{HERD}_{\mathrm{o}}+\varepsilon_{\mathrm{ijklmno}},
\end{aligned}
$$

where $Y_{\mathrm{ijklmno}}$ is the 90-d return to service following the first AI; $\alpha$ is the intercept; $\mathrm{EXP}_{\mathrm{i}}$ is the exposure status (28 or 63 classes); $\mathrm{LN}_{\mathrm{j}}$ is the parity (4 classes); $\mathrm{MY}_{\mathrm{k}}$ is the peak milk yield, expressed as the maximum at the 3 first test-day records in the lactation (5 classes); $\mathrm{PF}_{1}$ is the maximum of fat:protein ratio out of the 3 first test-day records (5 classes); $\mathrm{CAII}_{\mathrm{m}}$ is the calving-to-AI interval (7 classes); $\mathrm{MO}_{\mathrm{n}}$ is the month of $\mathrm{AI}$ ( 8 classes); $\mathrm{HERD}_{\mathrm{o}}$ is the herd number (random); and $\varepsilon_{\mathrm{ijklmno}}$ is the residual error term.

The random variable adjusted for clustering within the data. The effects in percentage points of return rate were calculated from estimated hazard ratio (HR). All statistical analyses were performed by using $\mathrm{R}$ software (R Development Core Team, 2009) and Cox models were performed using the survival package [Splus original by Terry Therneau and R port by Thomas Lumley; Therneau and Lumley (2008)].

\section{Simulated Fertility Losses at the Herd Level According to the Distribution of Al Over Time}

Once the at-risk period was identified, the fertility losses in an exposed herd were simulated according to the proportion of cows inseminated during this time interval. This proportion varies according to the management of the calving season in the herd. The fertility loss was defined as the average increase of return-toservice rate expressed in percentage points multiplied by the proportion of cows inseminated during the atrisk period of decreased fertility. The average increase in return-to-service rate was calculated for 2 scenarios. First, to estimate an overall effect of BTV-8 exposure, the average increase was calculated using HR estimated across the at-risk period in all case herds that were detected in September, including all exposed cantons (assuming September to have the most accurate dates of exposure). Second, to estimate an effect of BTV8 exposure only in highly exposed herds, the average increase was calculated using HR estimated across the at-risk period in herds detected in September in only highly exposed cantons. 
Finally, the simulated fertility losses were compared with the simulated detrimental effect of vaccination against BTV-8 in a herd. Decreased fertility has been demonstrated for cows receiving a second vaccine injection within 1 wk following AI (Feyer et al., 2011; Nusinovici et al., 2011). The fertility losses in a herd attributable to vaccination were calculated in a similar way as losses attributable to exposure, according to the proportion of cows inseminated during the at-risk period. This comparison contributes to the evaluation of the benefit/risk of the vaccination.

\section{RESULTS}

\section{Cumulative Prevalence in Exposed Cantons and Unadjusted Return-to-Service Rates}

The distribution of the cumulative prevalence in exposed cantons (at the end of 2007) showed wide variation (from 0.4 to $100 \%$; median $=17.9 \%$ ). Almost $67 \%$ of the BTV-8 cases were reported during September and October (Figure 2). For exposed dairy herds included in the analyses, the dates of exposure ranged from September 1 to December 26, 2007. Figure 3 shows both the geographical distribution of exposed cantons according to the class of exposure and the area-based reference unexposed population of cantons in 2007 in France.

The overall 90-d-return-to-service rate for cows in exposed herds was $59.0 \%$. In the reference populations, the overall 90-d-return-to-service rates for the areabased and time-based populations were 54.2 and $54.7 \%$, respectively (Table 1 ).

\section{Increase in 90-d-Return-to-Service Rates Associated with BTV-8 Exposure According to the Date of Exposure and the Local Geographical Area}

Exposure to BTV-8 was associated with an increase in 90-d-return-to-service rates (Figure 4). The effect of exposure on fertility was similar when comparing both reference populations (results with the time-based reference population are not shown here). Nevertheless, HR were slightly higher (differences $<0.1$ ) with the area-based reference population than with the timebased reference population.

Quantitatively, 90-d-return-to-service rates did not increase according to the level of exposure at the canton level. Thus, no correlation was observed between the effect of exposure on fertility and the level of exposure (peak monthly incidence) at the canton level during the epizootic (Figure 4).

The period of decreased fertility varied with the month of the disease detection. For herds in which dis- ease was detected in September, exposure was associated with an increase of 90-d-return-to-service rates for AI performed during a period from 1 mo before to 1 mo after the date of exposure (HR between 1.15 and 1.36). For herds in which disease was detected in November or December, exposure was associated with an increase in 90-d-return-to-service rates for AI performed between 10 and $4 \mathrm{wk}$ before the date of exposure (HR between 1.25 and 1.38). Interestingly, for the herds in which disease was detected in November or December, the AI were performed during the same time period as those for herds detected in September or October (Figure 4). Irrespective of the month of exposure but depending on the interval to the date of exposure, the increase in 90-d-return-to-service rate associated with BTV-8 exposure varied from 8 to 21 percentage points.

The following adjustment variables were significantly associated with a risk of 90-d return to service: parity, milk yield, fat:protein ratio and calving-to-AI interval. The risk was higher for multiparous cows and for cows with a higher milk yield. In contrast, the risk was lower for cows with a lower fat:protein ratio and for cows with a higher calving-to-AI interval (Table 2). Nevertheless, the effect of BTV-8 exposure on fertility was higher than the effect of the adjustment variables.

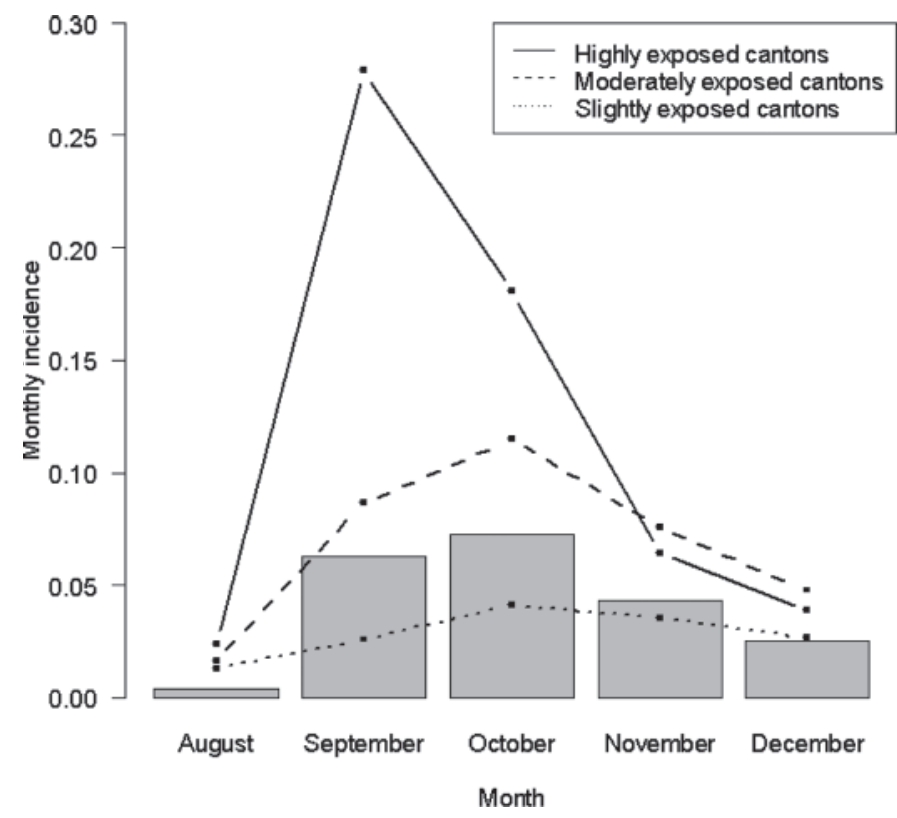

Figure 2. Average monthly incidence of bluetongue virus serotype 8 (BTV-8) cattle case herds in 2007 for the whole exposed area in France (bars) and according to the peak level of exposure in the canton (lines). Highly exposed cantons $=$ cantons with a peak incidence $\geq 0.25$; moderately exposed cantons: cantons with a peak incidence $\geq 0.10$ and $<0.25$; slightly exposed cantons $=$ cantons with a peak incidence $<0.10$. 
Table 1. Return-to-service rates and distribution of cantons, herds, and cows according to the bluetongue virus serotype 8 (BTV-8) exposure status $\left(10,722\right.$ Holstein dairy herds; 2007; France) ${ }^{1}$

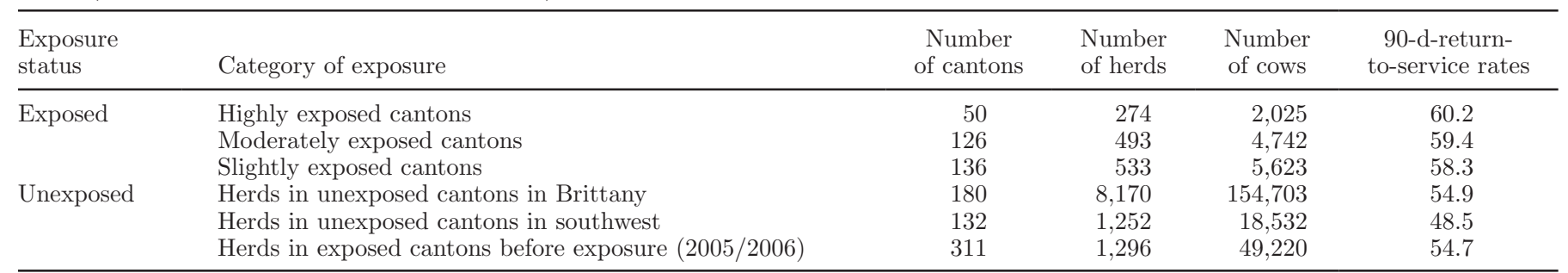

${ }^{1}$ Cows in exposed herds with first AI between $10 \mathrm{wk}$ before and 4 wk after the date of clinical detection in the herd. Highly exposed cantons $=$ cantons with a peak incidence $\geq 0.25$; moderately exposed cantons $=$ cantons with a peak incidence $\geq 0.10$ and $<0.25$; slightly exposed cantons $=$ cantons with a peak incidence $<0.10$.

\section{At-Risk Period for Decreased Fertility Associated with Exposure to BTV-8 Detected in Herds in September in Highly Exposed Cantons}

The risk of 90-d return to service was higher for those AI performed from 4 wk before to 5 wk after the date of exposure in the herd compared with unexposed cows (Figure 5). The effect was nonsignificant for cows inseminated between 14 and $5 \mathrm{wk}$ before the date of exposure and from 6 to $14 \mathrm{wk}$ after the date of exposure to BTV-8. Similar effects were demonstrated, regardless of which reference cow population was considered (results with the time-based reference population are not shown here). The estimated effects were increases of between 13.5 and 26.8 percentage points of $90-\mathrm{d}$ return to service.

\section{Simulated Fertility Losses at the Herd Level According to the Distribution of Al in Time}

An average increase of 15.3 percentage points of 90-d return to service was calculated for AI in herds for which disease was detected in September in highly exposed cantons. Given that $27.8 \%$ of the cows were

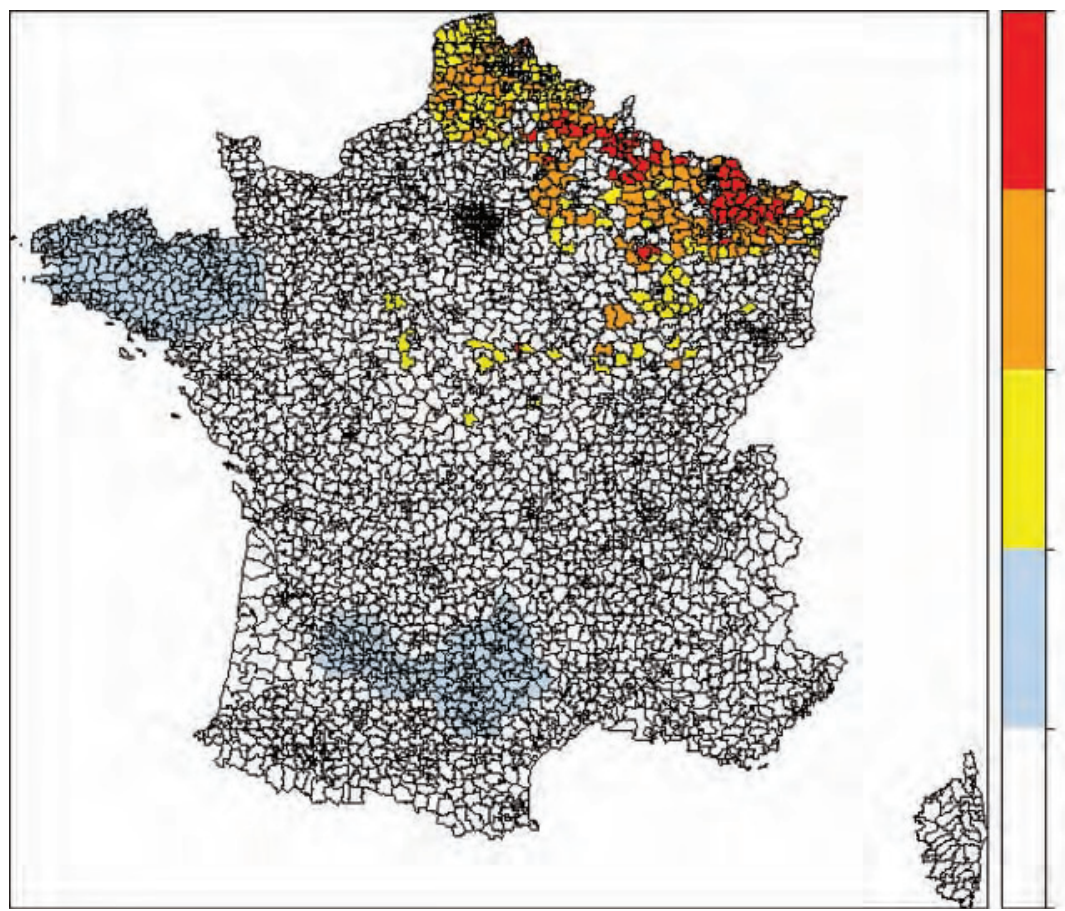

Highly exposed cantons

\section{Moderately exposed cantons}

\section{Slighly exposed} cantons

\section{Unexposed} cantons selected

\section{Cantons} not selected

Figure 3. Classification of cantons according to exposure to bluetongue virus serotype 8 (BTV-8) and location of unexposed cantons of the reference population in 2007 in France. Highly exposed cantons $=$ cantons with a peak incidence $\geq 0.25$; moderately exposed cantons $=$ cantons with a peak incidence $>0.10$ and $<0.25$; slightly exposed cantons $=$ cantons with a peak incidence $<0.10$; unexposed cantons selected $=$ cantons where no BTV-1 or BTV-8 cattle herd case was reported in 2007 and located in Brittany or in the southwestern part of France; cantons not selected $=$ either exposed or unexposed cantons that were not selected in the analyses. 


\section{Month of detection and month of $\mathrm{Al}$}

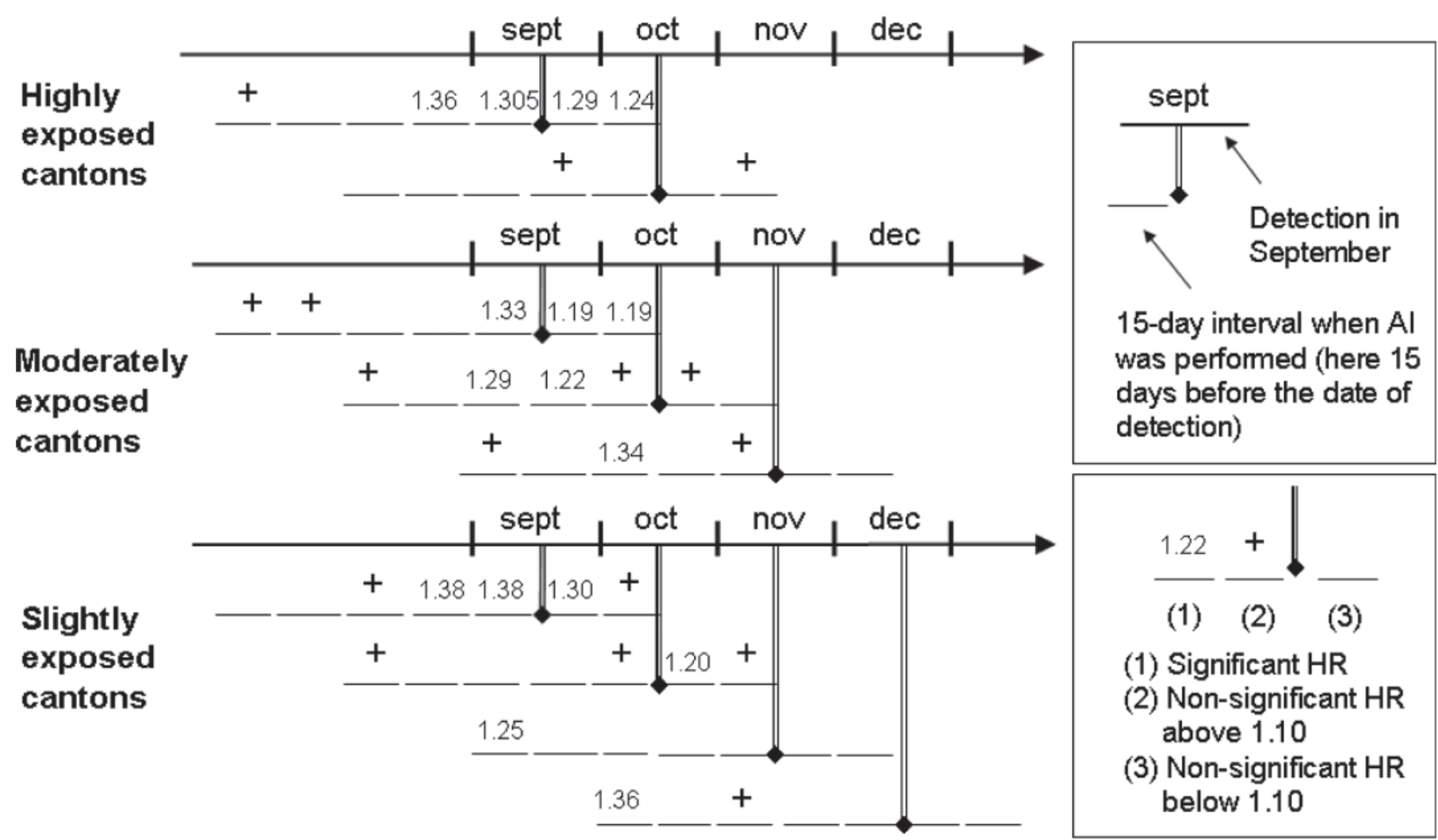

Figure 4. Hazard ratio (HR) of 90-d return to service according to the time interval between the date of AI of cows and the date of detection in the herd and to the category of bluetongue virus serotype 8 (BTV-8) exposure of the canton (12,390 cows in 1,300 exposed dairy herds). The unexposed cow population was composed of cows inseminated in the same time period in herds located in unexposed cantons (173,235 cows in 9,422 unexposed dairy herds) in 2007 in France. Highly exposed cantons $=$ cantons with a peak incidence $\geq 0.25$; moderately exposed cantons $=$ cantons with a peak incidence $\geq 0.10$ and $<0.25$; slightly exposed cantons $=$ cantons with a peak incidence $<0.10$.

inseminated during the at-risk period during the 2007 epizootic, the overall loss of fertility for the herd attributable to BTV-8 exposure was $4.2 \%$ (Figure 6a). When considering all of the exposed herds detected in September, irrespective of exposure at the canton level, the overall effect of BTV-8 exposure corresponded to an increase of 9.6 percentage points of 90-d return to service and, thus, the attributable fertility loss was $2.7 \%$ (Figure $6 \mathrm{a}$ ).

The fertility loss attributable to the vaccination against BTV-8 was calculated in a similar way. Given that $4.5 \%$ of the cows received a second vaccine injection within 1 wk following an AI in 2008 in Brittany and that the effect corresponded to an increase of 4.2 percentage points for 3 -wk return to service, the attributable fertility loss was equal to $0.19 \%$ (Figure 6a).

Considering the overall detrimental effects of BTV8 exposure in the 2007 field conditions and vaccination against BTV-8 in the 2008 field conditions, the detrimental effect of BTV-8 exposure on fertility was
22 times higher than the adverse effect of vaccination against BTV-8. However, if only $2 \%$ of the cows received a second vaccine injection during the period at risk of decreased fertility due to vaccination, this ratio increased to 50 (Figure 6b). The hatched area in Figure $6 \mathrm{~b}$ corresponds to herds for which the expected benefit of vaccination against BTV-8 by prevention of fertility losses would be smaller than the possible associated side effect on fertility. When considering all of the BTV-8-exposed herds detected in September, the detrimental effect of BTV-8 exposure on fertility was 14 times higher than the side effect of vaccination against BTV-8.

\section{DISCUSSION}

Exposure to BTV-8 was associated with a decrease in fertility for cows in dairy herds confirmed seropositive after clinical suspicion during the 2007 epizootic. The period of decreased fertility around the date of 
Table 2. Effect of adjustment variables on risk of 90-d return to service for cows that underwent AI during a period from $10 \mathrm{wk}$ before until $4 \mathrm{wk}$ after the date of bluetongue virus serotype 8 (BTV-8) detection in 10,722 Holstein dairy herds in 2007 in France

\begin{tabular}{|c|c|c|c|}
\hline $\begin{array}{l}\text { Variable } \\
\text { and class }\end{array}$ & $\begin{array}{l}\text { Number } \\
\text { of AI }\end{array}$ & $\begin{array}{c}\text { Hazard } \\
\text { ratio }\end{array}$ & $95 \% \mathrm{CI}$ \\
\hline \multicolumn{4}{|l|}{ Parity } \\
\hline 1 & 65,225 & 1 & Reference \\
\hline 2 & 49,013 & 1.105 & $1.09-1.12$ \\
\hline 3 & 33,836 & 1.14 & $1.12-1.16$ \\
\hline 4 or more & 37,558 & 1.25 & $1.23-1.27$ \\
\hline \multicolumn{4}{|c|}{ Milk yield $^{1}(\mathrm{~kg} / \mathrm{d})$} \\
\hline 1 & 23,958 & 0.94 & $0.85-0.92$ \\
\hline 2 & 47,036 & 0.97 & $0.95-0.98$ \\
\hline 3 & 57,148 & 1 & Reference \\
\hline 4 & 38,427 & 1.05 & $1.12-1.16$ \\
\hline 5 & 19,063 & 1.10 & $1.23-1.27$ \\
\hline \multicolumn{4}{|c|}{ Fat:protein ratio } \\
\hline$>0.67 ; \leq 1.20$ & 19,293 & 0.97 & $0.95-0.99$ \\
\hline$>1.20 ; \leq 1.33$ & 40,308 & 0.98 & $0.96-0.99$ \\
\hline$>1.33 ; \leq 1.51$ & 64,533 & 1 & Reference \\
\hline$>1.51 ; \leq 1.72$ & 40,375 & 1.03 & $1.02-1.05$ \\
\hline$>1.72 ; \leq 4$ & 21,123 & 1.04 & $1.02-1.06$ \\
\hline \multicolumn{4}{|c|}{ Calving-to-AI interval (d) } \\
\hline$>35 ; \leq 50$ & 10,807 & 1.20 & $1.16-1.23$ \\
\hline$>50 ; \leq 62$ & 35,842 & 1.13 & $1.11-1.15$ \\
\hline$>62 ; \leq 80$ & 54,079 & 1.06 & $1.045-1.08$ \\
\hline$>80 ; \leq 102$ & 43,337 & 1 & Reference \\
\hline$>102 ; \leq 125$ & 23,238 & 0.95 & $0.93-0.97$ \\
\hline$>125 ; \leq 150$ & 11,767 & 0.92 & $0.89-0.945$ \\
\hline$>150 ; \leq 180$ & 6,365 & 0.88 & $0.85-0.92$ \\
\hline \multicolumn{4}{|c|}{ Month of service } \\
\hline June & 15,010 & 0.92 & $0.895-0.95$ \\
\hline July & 14,989 & 0.97 & $0.94-0.995$ \\
\hline August & 17,357 & 0.99 & $0.97-1.02$ \\
\hline September & 21,485 & 1 & Reference \\
\hline October & 27,458 & 1.01 & $0.99-1.04$ \\
\hline November & 31,631 & 0.99 & $0.97-1.015$ \\
\hline December & 31,115 & 1.01 & $0.985-1.035$ \\
\hline January & 26,587 & 1.01 & $0.98-1.03$ \\
\hline
\end{tabular}

${ }^{1}$ Classes were constituted according to the distribution of milk yield and parity.

suspicion depended upon the month of detection of the disease in the herd. The increase in return-to-service rate associated with BTV-8 exposure varied from 8 to 21 percentage points. This value represented an average effect in natural exposure conditions, for which the proportion of infected cows in the exposed herds were unknown.

The effect of BTV-8 exposure on fertility did not correlate with the incidence of reported clinical cases of BTV-8 in the local geographical area. It was speculated that the number of newly infected herds per month was related to the proportion of infected cows within the exposed herds. Thus, 3 categories of cantons were defined. However, for a fixed interval between AI and the date of detection (within a selected month), no difference was observed between these categories of exposure. Two reasons could explain this result. The proportion of infected cows in selected exposed herds could be relatively constant and not related to the proportion of newly infected herds per month in a canton. Fur- thermore, the under-notification of BTV-8 case herds could be higher for late exposure during the epizootic, resulting in increased underestimation of incidences of BTV-8 case herds in moderately and slightly exposed cantons.

In highly exposed cantons, fertility was decreased in herds detected in September for those cows inseminated from $4 \mathrm{wk}$ before to $5 \mathrm{wk}$ after the date of detection. Within an exposed herd, it is probable that a proportion of cows are rapidly infected at the time of detection of the disease, with the rest of the herd either remaining uninfected or becoming infected at a later date. Exposure to BTV-8 could decrease the fertility of both cows infected around the time of AI (assuming an effect on conception failure or early embryonic mortality) and cows infected within $42 \mathrm{~d}$ of AI (assuming an effect on late embryonic mortality). Bluetongue virus serotype 8 infection is known to affect fetal development (Elbers et al., 2008, 2009; Wouda et al., 2009). However, given that fetal development commences $42 \mathrm{~d}$ after insemi- 


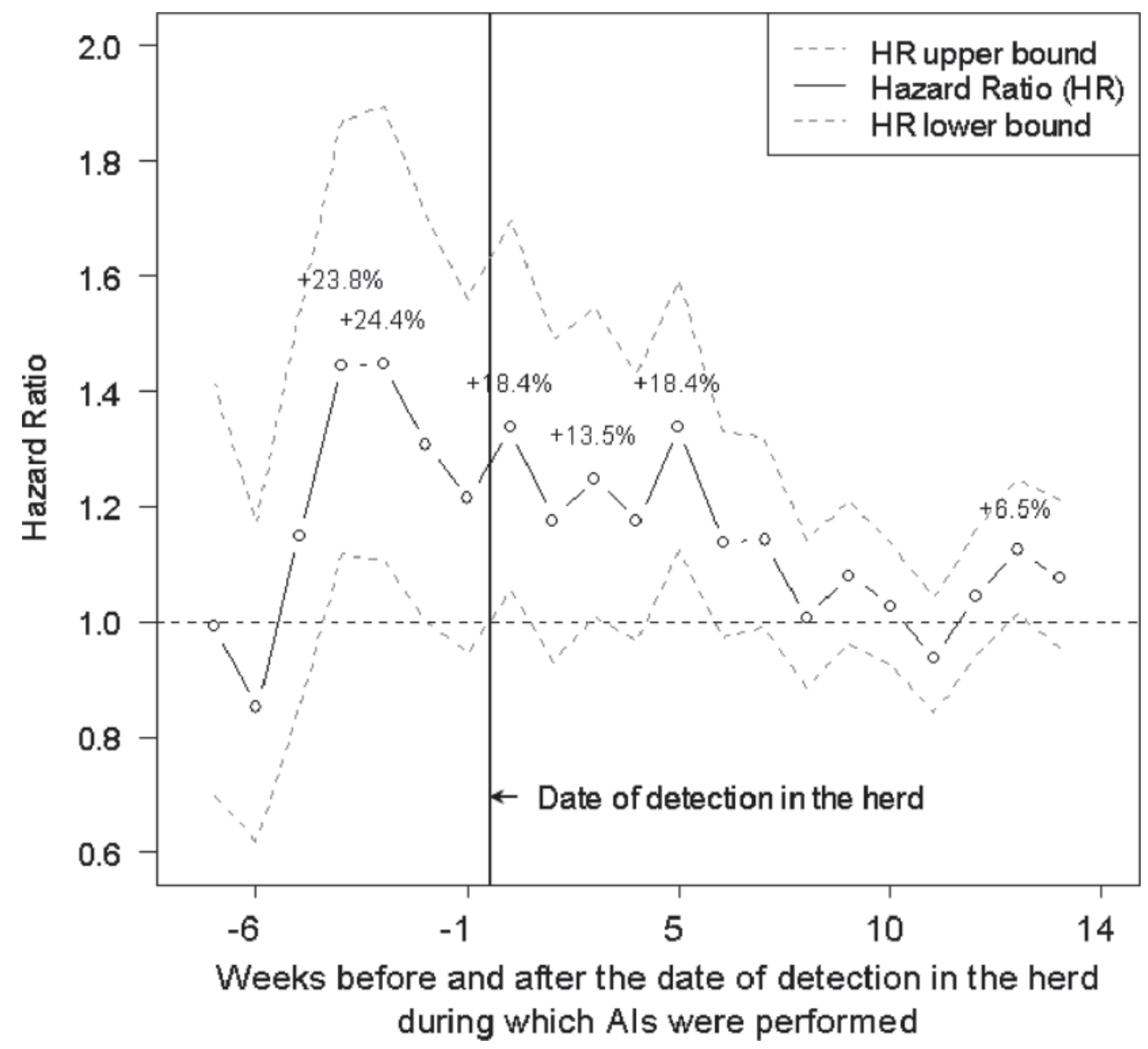

Figure 5. Increase in 90-d-return-to-service rates before and after the date of bluetongue virus serotype 8 (BTV-8) detection in herds detected in September in highly exposed cantons (6,714 cows in 419 exposed dairy herds). Highly exposed cantons $=$ cantons with a peak incidence $\geq 0.25$. The unexposed cow population was composed of cows inseminated in the same time period in herds located in unexposed cantons (173,235 cows in 9,422 unexposed dairy herds).

nation, and no decrease in fertility was observed for cows inseminated more than $42 \mathrm{~d}$ before bluetongue was detected, this study did not demonstrate a detrimental effect of BTV-8 exposure on fetal viability. Fetal infection can induce lethal malformations or the mummification of the fetus, leading to the birth of an abnormal calf or late pregnancy losses (possibly inducing a return to service occurring after $90 \mathrm{~d}$ post-AI). This study was not designed to detect these late loses. Moreover, for such late loses, the farmer may decide not to reinseminate the cow. In addition, BTV-8 infection could have a delayed effect on fertility related to the contamination and development of the virus in a cow's genital tract. Therefore, the variations of fertility in an exposed herd were likely due to the combined effect of the infection (both direct and delayed), and the delayed exposure of a proportion of cows due to the spreading of the virus within exposed herds. However, it was not possible to distinguish between these effects. Nevertheless, the effect of BTV-8 exposure on female fertility in herds detected in September lasted for an average of 5 wk after the detection of clinical signs in a herd.

The date of exposure of a herd to BTV- 8 was defined as the date of suspicion of clinical signs. However, this date did not actually correspond to the date of the first infection in exposed herds. The interval between first infection and the date of clinical suspicion is a composite of the viral incubation period and the time taken to detect the clinical signs and to subsequently report the case. The BTV incubation period is between 2 and $15 \mathrm{~d}$, depending on the serotype and the host species. Further, 2 studies conducted in Belgium and the Netherlands during the 2006 epizootic wave demonstrated that notification of new cattle outbreaks was 

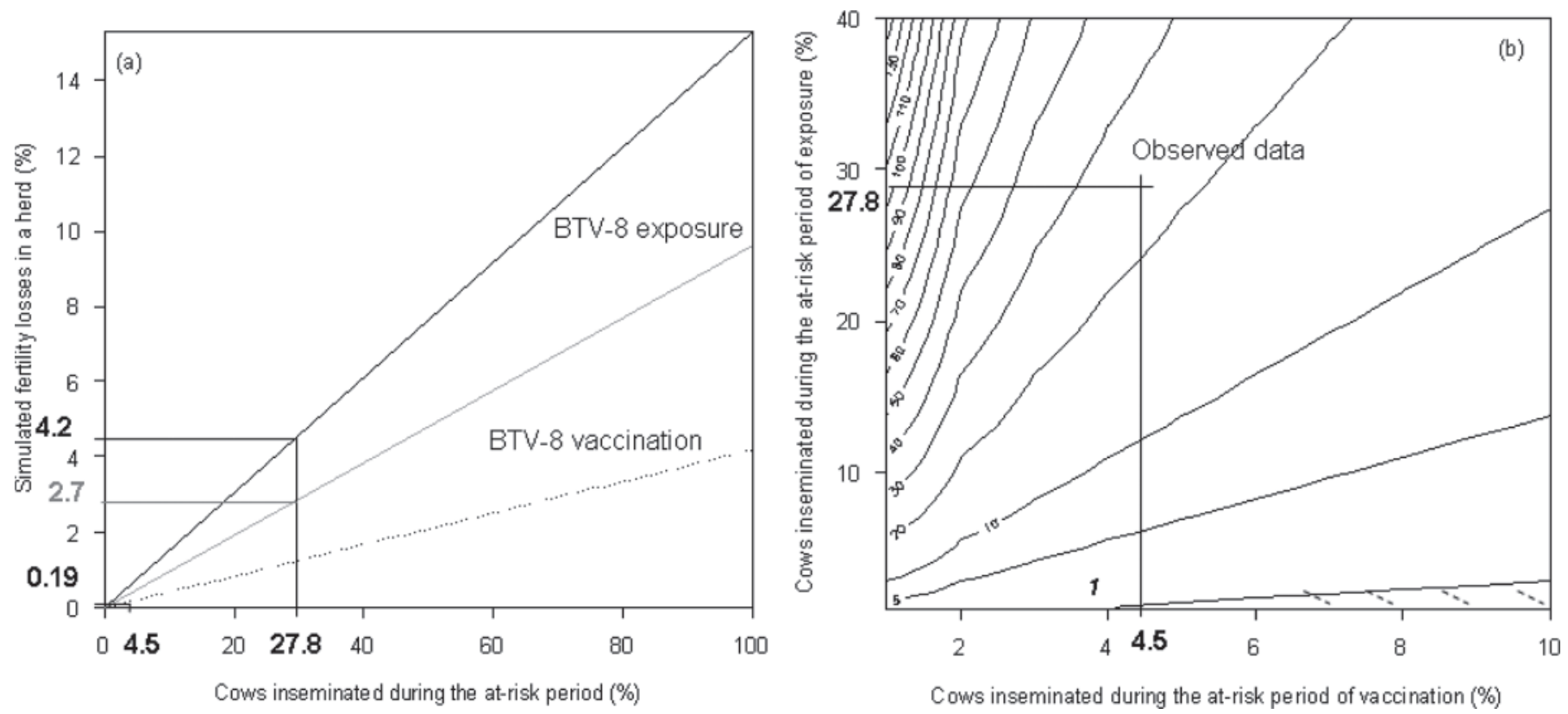

Figure 6. (a) Simulated fertility losses in a herd according to the proportion of cows inseminated during the 9-wk at-risk period of bluetongue virus serotype 8 (BTV-8) exposure (plain lines) and the 1-wk at-risk period of adverse effects of vaccination against BTV-8 (dashed lines). The black and gray plain lines correspond to fertility losses attributable to BTV-8 exposure based on overall increases of 15.3 (highest exposure) and 9.6 (all exposure) percentage points for cows inseminated from 4 wk before to 5 wk after the date of detection in the herd, respectively. For the fertility losses attributable to vaccination against BTV-8, an increase of 4.2 percentage points was considered for cows receiving a second vaccine injection within 1 wk after AI. (b) Ratio of the detrimental effects attributable to BTV-8 exposure and to vaccination against BTV-8 according to the proportion of cows inseminated during the at-risk periods. These simulations were based on an overall increase of 15.3 percentage points attributable to the BTV-8 exposure and an increase of 4.2 percentage points attributable to vaccination against BTV-8. The hatched area corresponds to herds for which the expected benefit of vaccination against BTV-8 would be smaller than the possible associated risks. In the study populations, the observed proportions of cows exposed (27.8\%) or vaccinated (4.5\%) during the at-risk periods resulted in a ratio exposure risk/ vaccination risk between 20 and 30 .

made within 1 or 2 wk of the first expressions of clinical signs (Elbers et al., 2008; Saegerman et al., 2010). Thus, the virus is likely to have already spread within exposed herds between 2 and 4 wk before the date of clinical suspicion. Therefore, for herds in which disease was reported in September 2007, the decreased fertility associated with AI performed before the nominated date of exposure could partly be due to the effect of viral circulation before clinical detection.

In contrast to September, for exposed herds in highly exposed cantons with a peak of monthly incidence in October, no significant effect on fertility was demonstrated. However, only 11 cantons had a peak of incidence greater than $25 \%$ in October (714 cows in 74 exposed herds), in comparison to 39 cantons with a peak of incidence greater than $25 \%$ in September $(1,311$ cows in 200 exposed herds). Therefore, the HR for this population of cows may have failed to detect significance partly due to the lack of statistical power.

For cows in case herds located in cantons with a peak of monthly incidence occurring in November and December, the estimated effects on fertility suggested that detection of exposure to BTV-8 was delayed. The episode of decreased fertility was associated with AI performed between 2 and 3 mo before the official date of detection in these herds. Indeed, the affected AI were performed during the overall peak of exposure (i.e., in September or October). This suggests that the virus could have been spreading in these herds before it was detected, either because clinical signs were not observed or because the viral circulation was too low to induce the expression of clinical signs in infected cows. The effect could also be due to an increase in fetal mortality. However, no such effect was demonstrated with the 90-d-return-to-service criteria for herds that were detected earlier, and it is very unlikely that such an effect would be found only for herds detected later during the epizootic. Furthermore, for cows that were inseminated $>4$ wk before the date of detection in herds detected in November and December, $20 \%$ of the extra 90-d return to service occurred before the date of detection in exposed herds (result not shown). This suggests that the decreased fertility occurred before the reported date of clinical detection.

The only published study that quantifies the effect of BTV-8 exposure on cows fertility was conducted in the 
Netherlands during the 2008 epizootic wave in herds that were not vaccinated (Santman-Berends et al., 2010). That study showed that cows that seroconverted to BTV-8 around the time of AI experienced a decrease in fertility equivalent to an increase of between 39.2 and 32.3 percentage points of return to service within $56 \mathrm{~d}$ of the first insemination, depending on the reference population of cows that did not seroconvert (cows that did not seroconvert in that same year or cows inseminated before seroconversion, respectively). This effect was quantified only in seroconverting cows, whereas in our analysis, all cows from infected herds were included, and a proportion of them are likely not to have been infected. It is, therefore, expected that their study could find a larger effect because all cows were infected. Besides, because of the low number of infected cows in their study, the confidence intervals of the estimates were wide. Assuming a similar biological effect of BTV8 infection in seroconverting cows reported here, the results would suggest that approximately $40 \%$ of the cows were infected in the French exposed herds (given an overall increase of $15 \%$ of return to service).

We considered 2 reference populations to limit misinterpretation due to variations in herd management between regions and variations of herd management over time within a given region. The effect on fertility and the duration of the at-risk periods associated with BTV-8 exposure when comparing to these 2 different reference populations was very similar. This confirms the robustness of the results. The comparability between the population of cows in exposed herds and cows in the 2 reference populations has been checked (results not shown). Fertility in case and control regions in 2005 did not differ. Similarly, fertility between 2005 and 2007 in the control region did not differ.

Fertility losses associated with either BTV-8 exposure or vaccination against BTV-8 depends on the proportion of cows inseminated during the respective at-risk periods. Given the number of cows inseminated during these at-risk periods, situations that increase the detrimental effect on fertility associated with the vaccination against BTV-8 are very unlikely, whereas infection is more likely to have a greater effect on fertility.

In this study, the detrimental effect of BTV-8 exposure was demonstrated for the first AI in Holstein cows. However, the negative effect of BTV-8 exposure on fertility is likely to be experienced for other breeds and subsequent $\mathrm{AI}$ in all unvaccinated cows inseminated during the same at-risk time interval.

This study quantified a significant negative effect of BTV-8 exposure on female fertility in dairy herds in which clinical cases of Bluetongue were confirmed during the 2007 epizootic in France. In case herds detected early in the epizootic, the episode of decreased fertility started $4 \mathrm{wk}$ before the date of detection of bluetongue in the herd and lasted for 5 wk after detection. The decrease in fertility during this period was due to a combination of the effect of infection (directly and delayed), and the spreading of the virus within exposed herds. For herds reported during the second half of the epizootic, the results indicated that clinical signs were detected late. Finally, compared with the low impact of vaccination against BTV-8 on fertility, the detrimental effect of BTV-8 exposure can lead to major losses in exposed herds.

\section{ACKNOWLEDGMENTS}

Financial support for this research was provided by INRA, Cemagref and Basse-Normandie, Bretagne, Pays de le Loire and Poitou-Charentes Regional Councils under the SANCRE project, in the framework of "For and About Regional Development" programs. The authors gratefully acknowledge the Centre de Traitement de l'Information Génétique (INRA, Jouy-en-Josas, France) for providing the performance data and the Ministry of Agriculture (Direction Générale de l'Alimentation) for the BTV case herds data. The authors also acknowledge Renaud Lancelot (CIRAD, Montpellier, France) for support in designing the imputation method.

\section{REFERENCES}

Dal Pozzo, F., C. Saegerman, and E. Thiry. 2009. Bovine infection with bluetongue virus with special emphasis on European serotype 8. Vet. J. 182:142-151.

Durand, B., G. Zanella, F. Biteau-Coroller, C. Locatelli, F. Baurier, C. Simon, E. Le Dréan, J. Delaval, E. Prengère, V. Beauté, and H. Guis. 2010. Anatomy of bluetongue virus serotype 8 epizootic wave, France, 2007-2008. Emerg. Infect. Dis. 16:1861-1868.

Elbers, A. R. W., A. Backx, E. Meroc, G. Gerbier, C. Staubach, G. Hendrickx, A. van der Spek, and K. Mintiens. 2008. Field observations during the bluetongue serotype 8 epidemic in 2006: I. Detection of first outbreaks and clinical signs in sheep and cattle in Belgium, France and the Netherlands. Prev. Vet. Med. 87:21-30.

Elbers, A. R. W., A. N. van der Spek, and P. A. van Rijn. 2009. Epidemiologic characteristics of bluetongue virus serotype 8 laboratoryconfirmed outbreaks in the Netherlands in 2007 and a comparison with the situation in 2006. Prev. Vet. Med. 92:1-8.

Feyer, D., D. Kemper, M. Reist, and T. Kaufmann. 2011. Bluetongue disease: Impact of the 2008 vaccination on fertility in supervised dairy herds. Schweiz. Arch. Tierheilkd. 153:257-262.

Heins, B. J., L. B. Hansen, and A. J. Seykora. 2006. Fertility and survival of pure Holsteins versus crossbreds of Holstein with Normande, Montbeliarde, and Scandinavian Red. J. Dairy Sci. 89:4944-4951.

Hillers, J. K., P. L. Senger, R. L. Darlington, and W. N. Fleming. 1984. Effects of production, season, age of cow, days dry, and days in milk on conception to first service in large commercial dairy herds. J. Dairy Sci. 67:861-867.

Le Mezec, P., A. Barbat-Leterrier, S. Barbier, R. de Crémoux, A. Gion, and C. Ponsart. 2010. Evolution de la fertilité et impact de la FCO sur la reproduction du cheptel laitier français. Pages 157-160 in Proc. Rencontre, Recherche, Ruminants. Institute de l'Elevage, INRA, Paris, France. 
Lucy, M. C. 2007. Fertility in high-producing dairy cows: Reasons for decline and corrective strategies for sustainable improvement. Soc. Reprod. Fertil. Suppl. 64:237-254.

Malher, X., F. Beaudeau, and J. M. Philipot. 2006. Effects of sire and dam genotype for complex vertebral malformation (CVM) on risk of return-to-service in Holstein dairy cows and heifers. Theriogenology 65:1215-1225.

Marcé, C., F. Beaudeau, N. Bareille, H. Seegers, and C. Fourichon. 2009. Higher non-return rate associated with Mycobacterium avium subspecies paratuberculosis infection at early stage in Holstein dairy cows. Theriogenology 71:807-816.

Menzies, F. D., S. J. McCullough, I. M. McKeown, J. L. Forster, S. Jess, C. Batten, A. K. Murchie, J. Gloster, J. G. Fallows, W. Pelgrim, P. S. Mellor, and C. A. L. Oura. 2008. Evidence for transplacental and contact transmission of bluetongue virus in cattle. Vet. Rec. 163:203-209.

Méroc, E., C. Faes, C. Herr, C. Staubach, B. Verheyden, T. Vanbinst, F. Vandenbussche, J. Hooyberghs, M. Aerts, K. De Clercq, and K. Mintiens. 2008. Establishing the spread of bluetongue virus at the end of the 2006 epidemic in Belgium. Vet. Microbiol. 131:133-144.

Nusinovici, S., H. Seegers, A. Joly, F. Beaudeau, and C. Fourichon. 2011. A side effect of decreased fertility associated with vaccination against bluetongue virus serotype 8 in Holstein dairy cows. Prev. Vet. Med. 101:42-50.

Osburn, B. I. 1994. The impact of bluetongue virus on reproduction. Comp. Immunol. Microbiol. Infect. Dis. 17:189-196.

Pioz, M., H. Guis, D. Calavas, B. Durand, D. Abrial, and C. Ducrot. 2011. Estimating front-wave velocity of infectious diseases: A simple, efficient method applied to bluetongue. Vet. Res. 42:60.

Raheja, K. L., E. B. Burnside, and L. R. Schaeffer. 1989. Heifer fertility and its relationship with cow fertility and production traits in Holstein dairy cattle. J. Dairy Sci. 72:2665-2669.

R Development Core Team. 2009. R: A language and environment for statistical computing. R Foundation for Statistical Computing, Vienna, Austria.
Robert, A., F. Beaudeau, H. Seegers, A. Joly, and J. M. Philipot. 2004. Large scale assessment of the effect associated with bovine viral diarrhoea virus infection on fertility of dairy cows in 6149 dairy herds in Brittany (Western France). Theriogenology 61:117-127.

Saegerman, C., D. Berkvens, and P. S. Mellor. 2008. Bluetongue epidemiology in the European Union. Emerg. Infect. Dis. 14:539-544.

Saegerman, C., P. Mellor, A. Uyttenhoef, J.-B. Hanon, N. Kirschvink, E. Haubruge, P. Delcroix, J.-Y. Houtain, P. Pourquier, F. Vandenbussche, B. Verheyden, K. De Clercq, and G. Czaplicki. 2010. The most likely time and place of introduction of BTV8 into Belgian ruminants. PLoS ONE 5:e9405.

Santman-Berends, I. M. G. A., J. J. Hage, P. A. van Rijn, J. A. Stegeman, and G. van Schaik. 2010. Bluetongue virus serotype 8 (BTV8) infection reduces fertility of Dutch dairy cattle and is vertically transmitted to offspring. Theriogenology 74:1377-1384.

Seegers, H. 1998. Performances de reproduction du troupeau bovin laitier: Variations dues aux facteurs zootechniques autres que ceux liés à l'alimentation. Pages 57-66 in Journées Nationales des GTV 1998.

Therneau, T., and T. Lumley. 2008. Survival: Survival analysis, including penalised likelihood. R package version 2.34-1. R Foundation for Statistical Computing, Vienna, Austria.

Uhaa, I. J., H. P. Riemann, M. C. Thurmond, and C. E. Franti. 1990. A cross-sectional study of bluetongue virus and Mycoplasma bovis infections in dairy cattle: II. The association between a positive antibody response and reproduction performance. Vet. Res. Commun. 14:471-480.

Velthuis, A. G. J., H. W. Saatkamp, M. C. M. Mourits, A. A. de Koeijer, and A. R. W. Elbers. 2010. Financial consequences of the Dutch bluetongue serotype 8 epidemics of 2006 and 2007. Prev. Vet. Med. 93:294-304.

Wouda, W., N. H. Peperkamp, M. P. Roumen, J. Muskens, A. van Rijn, and P. Vellema. 2009. Epizootic congenital hydranencephaly and abortion in cattle due to bluetongue virus serotype 8 in the Netherlands. Tijdschr. Diergeneeskd. 134:422-427. 